\title{
Trust: A Requirement for Cloud Technology Adoption
}

\author{
Akinwale O. Akinwunmi \\ Bowen University / Computer \\ Science and Information Technology \\ Department, Iwo, Nigeria
}

\author{
Emmanuel A. Olajubu \\ Obafemi Awolowo University, \\ Computer Science \& Engineering \\ Department, Ile-Ife, Nigeria
}

\author{
G. Adesola Aderounmu \\ Obafemi Awolowo University, \\ Computer Science \& Engineering \\ Department, Ile-Ife, Nigeria
}

\begin{abstract}
Cloud computing is a recent model for enabling convenient, on-demand network access to a shared pool of configurable computing resources such as networks, servers, storage, applications, and services; that can be rapidly provisioned and released with minimal management effort or service provider interaction. Studies have shown that cloud computing has the potential to benefit establishments, industries, national and international economies. Despite the enormous benefits cloud computing technology has the potentials of offering, several issues are making intended users to pause in adopting the usage of the technology. Users need to be assured of the safety and reliability of the technology while using it. This is needed to build confidence around the technology and reduce the level of anxiety. This research attempts to investigate the effect of trust in the adoption of the technology by formulating a trust model based on Expectancy Disconfirmation Theory model and Bayesian network. A simulation experiment was carried out to determine the significance of trust in the adoption of cloud technology.
\end{abstract}

\section{Keywords-Cloud; User; Adoption; Trust; Bayesian Network}

\section{INTRODUCTION}

A cloud is a type of parallel and distributed system consisting of a collection of inter-connected and virtualised computers that are dynamically provisioned and presented as one or more unified computing resources based on servicelevel agreements established through negotiation between the service provider and consumers [1]. Studies have shown that cloud computing has the potential to benefit establishments, industries, national and international economies [2, 3]. It can greatly accelerate the way companies create new products and services, making it possible for product development professionals around the world to interconnect and collaborate more effectively and gain access to more powerful and economical computer resources[2]; Increasing the ability of organizations to mine their data for important trend information, such as customers' changing needs and competitors moves in the market[2]; Levelling the playing field between large and small companies by giving companies of all sizes access to information technology that previously was affordable for only the largest of companies[2]; and Helping emerging economies leapfrog to higher levels of technological development by providing more immediate and affordable access to next- generation applications, tools, and infrastructure $[2,4]$. Cloud computing delivers infrastructure, platform, and software that are made available as subscriptionbased services in a pay-as-you-go model to consumers [5].
These services are referred to as Infrastructure as a Service (IaaS), Platform as a Service (PaaS), and Software as a Service (SaaS) in industries [6]. The importance of these services available from the long-held dream of computing as a utility has the potential to transform a large part of the IT industry, making software even more attractive as a service [7]. Cloud computing has been the new paradigm in distributed computing in the recent times. Cloud computing has been hailed as the 5th utility after electricity, gas, water and telephony as it promises to make the computing services available anywhere, any time and pay only for what is used or consumed [8].

Despite the enormous benefits cloud computing technology has the potentials of offering, several issues are making intended users to pause in adopting the usage of the technology. Users need to be assured of the safety and reliability of the technology while using it, this is required to build confidence around the technology. A new technology must gradually build its reputation for good performance and security, earning users' trust over time [9]. Most potential users are skeptical about the trustworthiness of cloud technology and this has been affecting the rate of its adoption. There is no way for the customer to be sure whether the management of the service is trustworthy, and whether there is any hidden risk [10]. This research attempts to investigate the effect of trust on the adoption of the cloud technology.

\section{RELATED WORKS}

Trust can be explained in diverse fields such as psychology, sociology, and economics. Also trust can be classified based on different meaning by many writers. Trust has been the focus of researchers for a long time [11], from the social sciences, where trust between humans has been studied to the effects of trust in economic transactions $[12,13,11]$. Although intuitively easy to comprehend, the notion of trust has not been formally defined [14]. Control is another important issue in trust. A system is trusted less when it is difficult to have the control over the assets in its custody. Trustworthiness plays an important role in service selection and usage of cloud services. Trust in cloud computing is related more to preventing a trust violation than to guaranteeing compensation should a violation occur. For most enterprises, a security breach of data is irreparable; no amount of money can guarantee to restore the lost data or the enterprise's reputation. The cloud computing trust model thus must focus more on preventing failure than on post-failure 
compensation [15]. A new technology must gradually build its reputation for good performance and security, earning users' trust over time [15]. Trust is a derivation of the reputation of an entity [14]. Based on the reputation, a level of trust is bestowed upon an entity [14].

Several leading research groups both in academia and the industry are working in the area of trust management in cloud computing. Dingguo et al. [16] proposed a trust cloud-based subjective trust assessment and management model. The model provided the design of trust cloud, the policy of the obtainment to compute the trust information and supplied trust decision based on trust cloud model [17]. Hada et al. [18] proposed a trust model for cloud architecture which uses mobile agent as security agents to acquire useful information from the virtual machine which the user and service provider can utilize to keep track of privacy of their data and virtual machines [18]. Combining quality of service (QoS) with trust model, Li et al. [19] constructed a QoS-aware and quantitative trust-model that consists of initial trust value [19], direct trust value, and recommendatory trust value of service, making the provision, discovery [19], and aggregation of cloud services trustworthy [19]. Khan and Malluhi [15] have looked at the trust in the cloud system from users' perspective [20]. They analyze the issues of trust from what a cloud user would expect with respect to their data in terms of security and privacy [20]. They further discuss that what kind of strategy the service providers may undertake to enhance the trust of the user in cloud services and provide r[20]. Sato et al. [21] have proposed a trust model of cloud security in terms of social security. The authors have identified and named the specific security issue as social insecurity problem and try to handle it using a three pronged approach [21]. The family gene based cloud trust model that is fundamentally different from the Public key Infrastructure based trust models have been proposed by several researchers [22,23]. These researchers have studied the basic operations such as user authentication, authorization management and access control, and proposed a Family-gene Based model for Cloud Trust (FBCT) integrating these operations [20].

Manuel et al. [24] have proposed trust model that is integrated with CARE (Center for Advanced Computing Research and Education) resource broker. This trust model can support both grid and cloud systems [24]. The model computes trust using three main components namely, Security Level Evaluator, Feedback Evaluator and Reputation Trust Evaluator [20]. Both Shen et al. [25] and Shen and Tong [26] have analyzed the security of cloud computing environment and described the function of trusted computing platform in cloud computing.

Alhamad et al. [27] have proposed a SLA (Service Level Agreement) based trust model for cloud computing. The model consists of the SLA agents, cloud consumer module, and cloud services directory. A model called a multi-tenancy trusted computing environment model (MTCEM) for cloud computing has been proposed by Li et al. [28]. MTCEM has been proposed to deliver trusted IaaS to customers with a dual level transitive trust mechanism that supports a security duty separation function simultaneously [28]. Fu et al. [29] have studied the security issues associated with software running in the cloud and proposed a watermark-aware trusted running environment to protect the software running in the cloud. Ranchal et al.[30] have studied the identity management in cloud computing and proposed a system without the involvement of a trusted third party. Takabi et al. [31] have proposed a security framework for cloud computing consisting of different modules to handle security, and trust issues of key components. Noor and Sheng [32] proposed the "Trust as a Service" (TaaS) framework to improve ways on trust management in cloud environments. In particular, an adaptive credibility model that distinguishes between credible trust feedbacks and malicious feedbacks by considering cloud service consumers' capability and majority consensus of their feedbacks was introduced [32]. Reputation-based trust is emerging as a good choice to model trust of cloud service providers based on available evidence [32]. Many existing reputation based systems either ignore or give less importance to uncertainty linked with the evidence [32]. Pawar et al. [33] proposed an uncertainty model and define the approach to compute opinion for cloud service providers. Using subjective logic operators along with the computed opinion values, mechanisms to calculate the reputation of cloud service providers were proposed [33].

In order to protect the security of cloud entities and better practice cloud's objectives of providing low-cost and ondemand services, Li et al. [34] proposed a novel cloud trust transaction framework and also a new trust fuzzy comprehensive evaluation based cloud service discovery algorithm. Prajapati et al.[35] presented a formal trust management model based on the basics of the trust characteristics. The proposed model was capable to handle various cloud services access scenarios where entity has a past experience with the service or a stranger entity requesting to access the service without any identity or past interaction with the service [35]. The work defined the direct trust with a timevariant evaluation method and the recommended trust with a space variant evaluation method. Motivated by human nature, the model also has considered the reputation factor of trustor to calculate the direct trust [35]. The proposed approach also has used the satisfaction level to calculate recommended trust which is depends on service level agreements of the services resides in the cloud environment [35]. Trust has attracted extensive attention in social science and computer science as a solution to enhance the security of the system. Wu et al. [36] proposed a trust evaluation model based on D-S evidence theory and sliding windows for cloud computing. The timeliness of the interaction evidence as the first-hand evidence is reflected by introducing sliding windows [36]. In an open and dynamic environment of distributed system such as cloud technology trust plays a major role in determining the level of adoption of the technology. Trust is one of the most concerned obstacles for the adoption and growth of cloud computing.

Threats, risks and other security concerns are impeding the move to cloud environment by individuals and organizations. Due to the transfer of substantial part of control of activities to a third party concerns are generated about the trustworthiness of the technology. Most of the efforts at making cloud technology trustworthy are still at infant stage. 


\section{THEORETICAL BACKGROUND}

The following concepts provide the theoretical basis for the solution proposed in this work with a view to achieving reliable and trustworthy cloud technology adoption model. These concepts are Expectancy Disconfirmation Theory (EDT) and Bayes' Theorem. The capability of Bayesian network to handle the complexity of the dynamism of the cloud environment and the perceived influence of service satisfaction in cloud computing usage informed the idea of conceptualizing a trust model based on the EDT Model and Bayesian Network.

Expectancy Disconfirmation Theory (EDT) is a theory for measuring customer satisfaction from perceived quality of products or services. EDT is a prominent theory from marketing that can predict and explain consumers' satisfaction with products or services. EDT has been applied most often in IT adoption or IT usage studies [37,38,39,40].

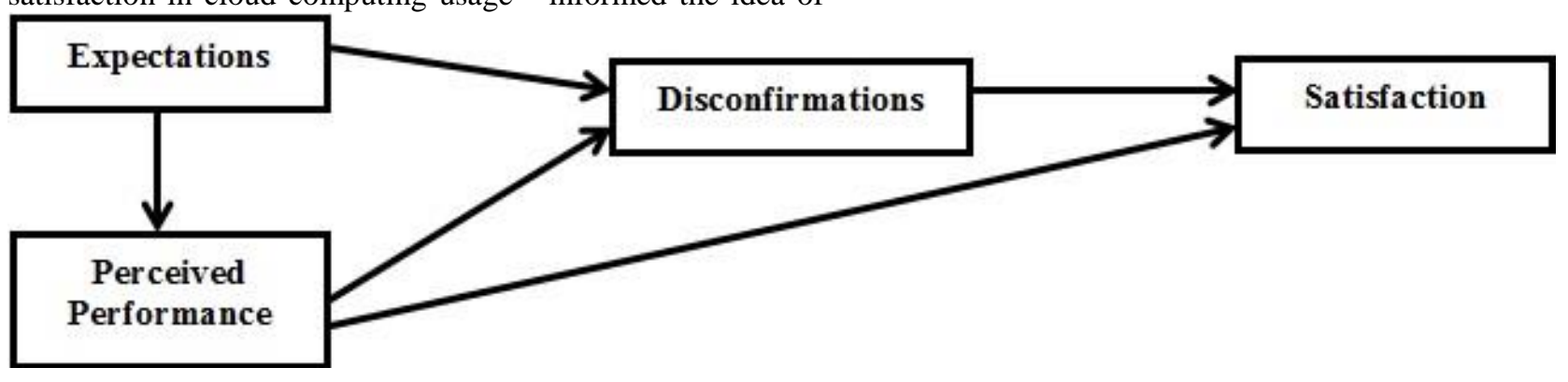

Fig. 1. Expectancy Disconfirmation Theory model [44]

The theory argues that 'satisfaction is related to the size and direction of the disconfirmation experience that occurs as a result of comparing service performance against expectations' [41]. It is a judgment that a product or service feature, or the product or service itself, provided (or is providing) a pleasurable level of expectation. This model consists of four components: expectations, perceived performance, disconfirmation, and satisfaction as shown in Fig. 1.

Expectations define the customer's anticipations about performance of products and services [42]. Perceived performance investigates the customer's experience after using products or services that can be better or worse than customer's expectation [43]. Disconfirmation is defined as the difference between the customer's initial expectation and observed actual performance [39].

The theory proposes that users first form expectations or belief probabilities of attribute occurrence. They then form post-usage perceptions about performance and a comparison between initial expectations and performance known as disconfirmation of expectations [44]. A positive disconfirmation means performance was better than expected, and a negative disconfirmation means performance was worse than expected. According to EDT, the better performance is, or the more positive the disconfirmation, the greater the satisfaction [44].
Bayes' Theorem is a mathematical formula used for calculating conditional probabilities. It figures prominently in subjectivist or Bayesian approaches to epistemology, statistics, and inductive logic. Subjectivists, who maintain that rational belief is governed by the laws of probability, lean heavily on conditional probabilities in their theories of evidence and their models of empirical learning [45]. Bayes' Theorem is central to these enterprises both because it simplifies the calculation of conditional probabilities and because it clarifies significant features of subjectivist position [45]. Bayesian Networks (BNs) provide a method for representing relationships between variables (called 'nodes' in the BN) even if the relationships involve uncertainty. They can be a useful modeling tool in situations where different types of variables and knowledge from various sources need to be integrated within a single framework $[46,47]$.

\section{PROPOSED MODEL}

The proposed model is based on the marriage of EDT model and Bayesian network. The end result of being satisfied with a technology usage is that trust will be built around the technology and this will influence potential users. Hence EDT model's components are transformed into a Bayesian network nodes ending with a trust node and the probabilities dependencies among the various components are depicted in Fig. 2.

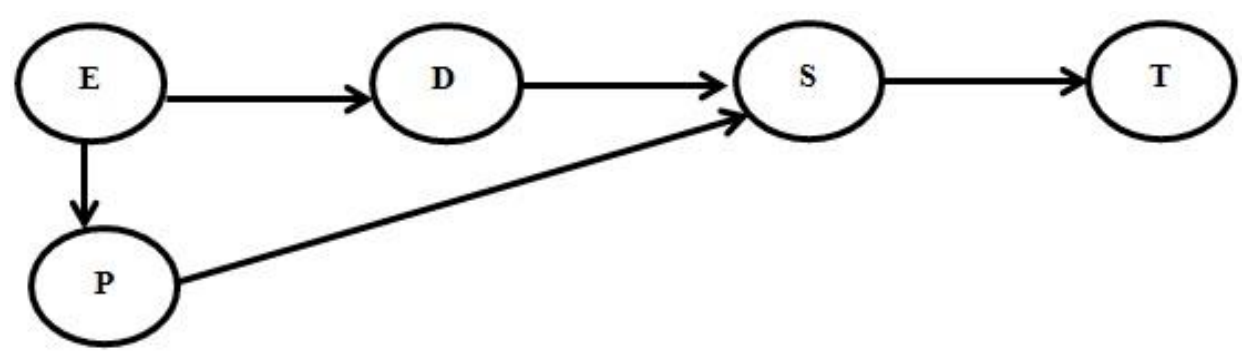

Fig. 2. Proposed Model Bayesian Network 
The notation used for the model variables are as follows: $\mathrm{E}$ stands for expectation, $\mathrm{P}$ for perceived performance, D stands for disconfirmation, $\mathrm{S}$ stands for satisfaction and $\mathrm{T}$ stands for trust as shown in Fig. 2.

The model is formulated using the chain rules of conditional probability, the full joint probability distribution for the model is written as a product of the individual density functions, conditional on their parent variables as depicted in equation 1 .

$\mathrm{P}(\mathrm{T}, \mathrm{S}, \mathrm{P}, \mathrm{D}, \mathrm{E})=\mathrm{P}(\mathrm{T} \mid \mathrm{S}) * \mathrm{P}(\mathrm{S} \mid \mathrm{D}, \mathrm{P}) * \mathrm{P}(\mathrm{P} \mid \mathrm{E}) * \mathrm{P}(\mathrm{D} \mid \mathrm{E}) * \mathrm{P}(\mathrm{E})$

Now suppose we use a cloud service with $S$ level of satisfaction. Let $\mathrm{S}(\mathrm{T})$ be the event that the cloud service is trusted. Let $\mathrm{P}(\mathrm{S})$ be the event that the cloud service is satisfactory. The events $\mathrm{S}(\mathrm{T})$, that the cloud service is trusted, and $\mathrm{S}(\bar{T})$, that the service is not trusted, partitioning the set of all cloud services. Hence, by Bayes' Theorem, the probability that the cloud service is trusted, given that it is satisfactory is shown in equation (2).

$\mathrm{P}(\mathrm{T} \mid \mathrm{S})=\frac{P(S \mid T) P(T)}{P(T \mid S) P(S)+P(T \mid \bar{S}) P(\bar{S})}$

To apply this formula, we first estimate $P(S)$, the probability that the cloud service is satisfactory, as well as $P(\bar{S})$, the probability that the cloud service is not satisfactory. Without prior knowledge about the likelihood that the cloud service is not satisfactory, simplicity we assume that the cloud service is equally likely to be satisfactory as it is not to be satisfactory. That is, we assume that $P(S)=P(\bar{S})=1 / 2$. Using this assumption, we find that the probability that the cloud service is equally likely to be satisfactory, is stated in equation (3)

$\mathrm{P}(\mathrm{T} \mid \mathrm{S})=\frac{P(S \mid T)}{P(S \mid T)+P(S \mid \bar{T})}$

Determining a specific model, $\mathrm{T}$, that best accounts for all the variations of cloud service usage can be accomplished by maximizing the level of cloud service satisfaction, $S$ which according to Bayes' rule is stated in equation 4.

$P(T \mid S) \alpha P(S \mid T) P(T)$

Determining the prior, $P(T \mid S)$, is full of uncertainty, then the model that maximizes the likelihood, $L(S \mid T)$ is chosen. The likelihood is proportional to the probability of observing the model T, treating the level of cloud service satisfaction, $\mathrm{S}$ as variables and the model $\mathrm{T}$ as fixed. The best estimator $\widehat{\mathrm{S}}$, is whatever value of $\widehat{S}$ that maximizes the likelihood is shown in equation (5).

$L(\hat{S} \mid T)=P(T \mid \hat{S})$

Typically the parameter $\widehat{\mathrm{S}}$ maximized the likelihood of observing the model T.
Based on the proportional relationship as expressed in equation (5), the $\widehat{S}$ that maximizes $L(\hat{S} \mid T)$ will also maximize $P(T \mid \hat{S})$ which is the probability of the observed model. $\widehat{\mathrm{S}}$ denotes the best satisfaction parameter for the model $\mathrm{T}$.

The likelihood function in equation (5) then is expressed as $\log$ likelihood function as shown in equation (6) $\log$ likelihood expression

$$
\operatorname{In} L=\operatorname{In} P(T \mid \hat{S})
$$

\section{SimUlation, RESUlT AND DisCUSSION}

Experiments were conducted to investigate the effect of trust in cloud environment using transaction's response time as the evaluation criterion in two different settings. The response time in this regard refers to time lag between the instant of service request by the users to the instant of having the result of the service request. This depends on round trip time (RTT) and the users' load.

The experiment looked at the cloud transactions carried out without involving trust factor against the same kind of cloud transaction involving trust factor in order to investigate their difference. CloudAnalyst [48] useful to model and analyze large scale cloud computing development was used for the simulation. Considering the description and behaviour of throttled load balancing policy of the CloudAnalyst, the integration of trust capability in cloud environment was achieved using this policy while the round-robin load balancing policy, considering its behaviour was used for the cloud transaction without trust integration.

The first setting simulated cloud service transaction platform using CloudAnalyst. In this experiment there are $5,10,15,20,25$ and 30 groups of users with a cloud provider. These group of users were generated randomly using Poisson distribution by varying the number of users in a realistic manner.

The detailed parameter settings for the experiment are shown in Table 1. In this experiment, the numbers of users were varied while the number of the provider was fixed in order to observe the behaviour of the cloud environment without trust integration and cloud environment with trust integration in terms of the transaction's response time.

Table 2 shows the results obtained from the simulation. The graph in Fig. 3 shows the plot of the round trip time against the number of group of users. From the results, the cloud environment with trust integration ensures relatively quick response time than the cloud environment without trust integration with slow response time. This is evident from the percentage difference of the response time as shown in Table 2. It was observed that integration of trust into the cloud environment is accountable for the quick response time achieved in the simulated cloud transaction with trust integration. 
TABLE I. SIMULATION PARAMETER SETTINGS FOR RESPONSE TIME WITH VARIED NUMBER OF USERS AND FIXED NUMBER OF PROVIDERS

\begin{tabular}{lllll}
\hline Users & Provider & $\begin{array}{l}\text { User } \\
\text { Growth } \\
\text { Factor }\end{array}$ & $\begin{array}{l}\text { Request } \\
\text { Growth } \\
\text { Factor }\end{array}$ & $\begin{array}{l}\text { Execution } \\
\text { Instruction Per } \\
\text { Length }\end{array}$ \\
\hline 5 & 1 & 10 & 10 & 100 \\
10 & 1 & 10 & 10 & 100 \\
15 & 1 & 10 & 10 & 100 \\
20 & 1 & 10 & 10 & 100 \\
25 & 1 & 10 & 10 & 100 \\
30 & 1 & 10 & 10 & 100 \\
\hline
\end{tabular}

TABLE II. RESPONSE TIME WITH VARIED NUMBER OF USERS AND FIXED NUMBER OF PROVIDERS IN CLOUd ENVIRONMENT WITHOUT TRUST AND WITH TRUST

\begin{tabular}{llll}
\hline $\begin{array}{l}\text { Number of } \\
\text { Users }\end{array}$ & $\begin{array}{l}\text { Round Trip } \\
\text { Time (ms) } \\
\text { (without trust) }\end{array}$ & $\begin{array}{l}\text { Round Trip } \\
\text { Time (ms) } \\
\text { (with trust) }\end{array}$ & $\begin{array}{l}\text { Percentage Difference } \\
(\%)\end{array}$ \\
\hline 5 & 300.49 & 300.39 & -0.03 \\
10 & 300.40 & 300.58 & 0.06 \\
15 & 300.70 & 300.16 & -0.18 \\
20 & 300.95 & 300.25 & -0.23 \\
25 & 300.37 & 300.23 & -0.05 \\
30 & 300.64 & 300.27 & -0.12 \\
\hline
\end{tabular}

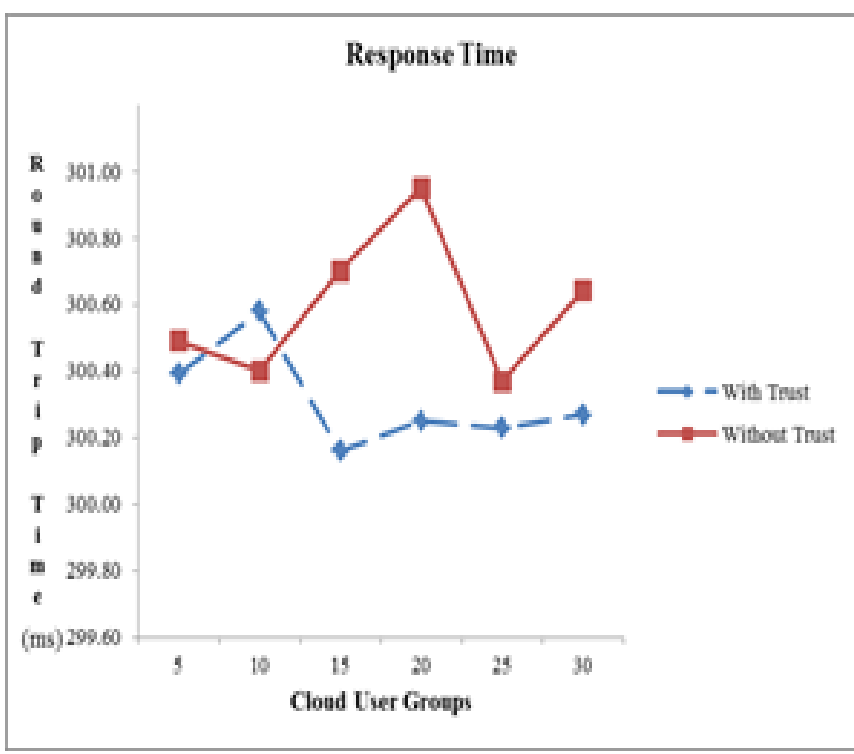

Fig. 3. Response time with varied number of users and fixed number of providers

In the second simulation experiment cloud transaction was also simulated using cloudAnalyst. Also throttled load balancing policy of the CloudAnalyst was used for the integration of trust capability in cloud environment while the round-robin load balancing policy, was used for the cloud transaction without trust integration. In this experiment there are $5,10,15,20,25$ and 30 groups of cloud users with a varied number of cloud providers. This group of users was generated randomly using Poisson distribution by varying the number of users in a realistic manner. The detailed parameter settings for the experiment were shown in Table 3. In this experiment, the number of group of users were varied as well as the number of the providers in order to observe the behaviour of the cloud environment without trust integration and with trust integration in terms of the transaction's response time.

TABLE III. Simulation Parameter Settings for Response Time WITH VARIED NUMBER OF USERS AND VARIED NUMBER OF PROVIDERS

\begin{tabular}{ccccc}
\hline Users & Provider & $\begin{array}{c}\text { User } \\
\text { Growth } \\
\text { Factor }\end{array}$ & $\begin{array}{c}\text { Request } \\
\text { Growth } \\
\text { Factor }\end{array}$ & $\begin{array}{c}\text { Execution } \\
\text { Instruction Per } \\
\text { Length }\end{array}$ \\
\hline 5 & 1 & 10 & 10 & 100 \\
10 & 2 & 10 & 10 & 100 \\
15 & 3 & 10 & 10 & 100 \\
20 & 4 & 10 & 10 & 100 \\
25 & 5 & 10 & 10 & 100 \\
30 & 6 & 10 & 10 & 100 \\
\hline
\end{tabular}

Table 4 shows the results obtained from the simulation. The graph in Fig.4 shows the plot of the round trip time against the group of users. From the results, cloud environment with trust integration ensures quicker response time than the cloud environment without trust integration with pretty much higher and unstable response time interval. This is evident from the percentage difference of the models' response time as shown in Table 4. It was observed that integration of trust into the cloud transaction is responsible for the quick response time of the cloud environment.

TABLE IV. RESPONSE TIME WITH VARIED NUMBER OF USERS AND VARIED NUMBER OF PROVIDERS IN CLOUD ENVIRONMENT WITHOUT TRUST AND WITH TRUST

\begin{tabular}{llll}
\hline $\begin{array}{l}\text { Number of } \\
\text { Users }\end{array}$ & $\begin{array}{l}\text { Round Trip } \\
\text { Time (ms) } \\
\text { (without trust) }\end{array}$ & $\begin{array}{l}\text { Round Trip } \\
\text { Time (ms) } \\
\text { (with trust) }\end{array}$ & $\begin{array}{l}\text { Percentage } \\
\text { Difference }(\%)\end{array}$ \\
\hline 5 & 300.49 & 300.39 & -0.033 \\
10 & 300.65 & 300.49 & -0.053 \\
15 & 302.62 & 300.45 & -0.717 \\
20 & 300.88 & 300.87 & -0.003 \\
25 & 301.63 & 300.55 & -0.358 \\
30 & 301.13 & 300.61 & -0.173 \\
\hline
\end{tabular}

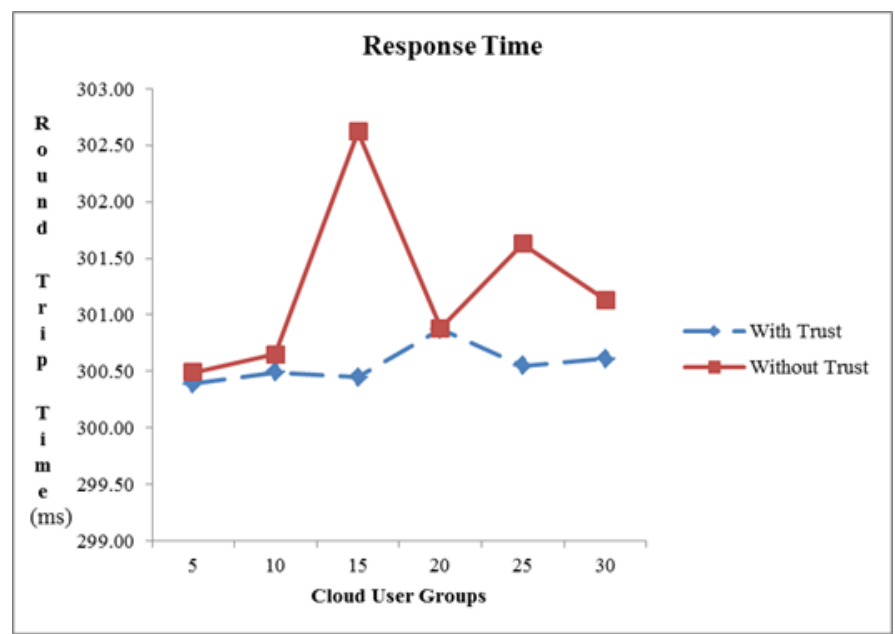

Fig. 4. Response Time with varied number of users and varied number of providers 
In order to validate the results of the simulation of the cloud transaction with trust integration and the cloud transaction without trust integration, $t$-test was used. This was used to compare the simulation results $[49,50]$ for the response time of the cloud transactions in the two different simulation settings to determine if there is any significant difference between them or not as a result of trust integration in the cloud environment. From the simulation results, the cloud transaction with trust performed better than the cloud transaction without trust. In order to validate simulation results, paired difference $t$-test was performed on the percentage difference of the response time with six group sizes in the two different simulation settings for the cloud transaction with trust and the cloud transaction without trust. The Null hypothesis states that there is no significant difference between the cloud transaction with trust and the cloud transaction without trust while the alternative hypothesis states that there is significance difference between them.

The calculated $t$ values for the response time in the two different experimental settings are -23.66, and -6.06, respectively as shown in Table 5 .

\begin{tabular}{|c|c|c|}
\hline \multirow[t]{4}{*}{ TABLE V. } & \multicolumn{2}{|c|}{$\begin{array}{c}\text { Calculated T Values For the Without } \\
\text { Trust }\end{array}$} \\
\hline & $\begin{array}{l}\text { Performance } \\
\text { Metrics }\end{array}$ & $\begin{array}{l}\text { Calculated T } \\
\text { Value }\end{array}$ \\
\hline & $\begin{array}{l}\text { Response Time } \\
\text { (Experiment one) }\end{array}$ & -23.66 \\
\hline & $\begin{array}{l}\text { Response Time } \\
\text { (Experiment two) }\end{array}$ & -6.06 \\
\hline
\end{tabular}

The degree of freedom for the total group size of six (6) is five (5). Entering a $t$ table with 5 degrees of freedom (df), at $95 \%$ confidence interval, the table $t$ value is 2.02 (one-tailed, a significance level ( $\alpha$ ) of 0.05 ). The absolute calculated $t$ values are higher than the tabled $t$ value of 2.02 showing that the cloud environment with trust integration with lower response time is significantly different $(\mathrm{p}=0.05)$ from the cloud environment without trust integration as a result trust integration in it.

\section{CONCLUSION}

The investigation carried out revealed that trust is required for achieving effective cloud technology adoption. The usage of cloud technology can lead to satisfaction, while satisfaction can aid in building trust in the technology and trust will lead to usage continuance intentions. Trust in a cloud service when properly addressed will positively affect cloud technology adoption. In accordance with the EDT model, satisfying the potential cloud users is not limited only to their expectation about cloud service. But also satisfying the cloud users from perceived performance is the first step that can attract the user's trust over offered cloud services. This line of research shows that trust in a cloud service can lead to perceived usefulness or other positive perceptions of the cloud services. Trust will positively influence the intention to use cloud services and the quality of prior experience will positively influence trust in cloud service provider's ability. The extent of prior experience will moderate the relationship between trust and intention to use cloud technology. Trust is a predicated factor needed for achieving higher rate of cloud adoption and facilitate effective usage of the cloud technology. Future work will consider parameters and factors that can help build and sustain trust in cloud environment for aiding fast cloud technology adoption. Developing techniques that demonstrates that the technology can be trust will also be considered.

\section{REFERENCES}

[1] Buyya, R., Yeo, C. S. and Venugopal, S., "Market oriented Cloud Computing: Vision, Hype, and Reality for Delivering IT Services as Computing Utilities" In Proceedings of the 10th IEEE International Conference on High Performance Computing and Communications (HPCC), 2008, Dalian, China.

[2] World Economic Forum, "Exploring The Future of Cloud Computing: Riding The Next Wave of Technology-Driven Transformation", Report of World Economic Forum In Partnership with Accenture 91-93 route de la Capite, 2010, CH-1223 Cologny/Geneva, Switzerland.

[3] Carcary, M., Doherty, E. and Conway, G. "The Adoption of Cloud Computing by Irish SMEs - an Exploratory Study" The Electronic Journal Information Systems Evaluation Vol.17 Issue 1 2014, (003- 014) , available online at www.ejise.com).

[4] John W. Rittinghouse and James F. Ransome Cloud Computing Implementation, Management, and Security CRC Press Taylor \& Francis Group 6000 Broken Sound Parkway NW, Suite 300 Boca Raton, FL 33487-2742 2010 by Taylor and Francis Group LLCCRC Press is an imprint of Taylor \& Francis Group, an Informa business

[5] Buyya, R. 2013 Market-oriented cloud computing: Opportunities and challenges Enterprise Distributed Object Computing Conference (EDOC), 2013 17th IEEE International Vancouver, BC, Canada 9-13 Sept. 2013 pg. 3, IEEE

[6] Calheiros,R.N., Ranjan,R., Beloglazov, A., De Rose, C.A.F and Buyya, R. (2011) "CloudSim: A Toolkit for Modeling and Simulation of Cloud Computing Environments and Evaluation of Resource Provisioning Algorithms". Software Practice Experience, 41:23-50.

[7] Armbrust, M., Fox, A., Griffith, R., Joseph, A., Katz, R., Konwinski, A., Lee, G., Patterson, D., Rabkin, A., Stoica, I. and Zaharia, M. (2010). A View of Cloud Computing. Communications of the ACM Volume 53, Number 4 (2010), Pages 50-58, USA.

[8] Buyya,R., Yeo, C., Venugopal, S., Broberg, J. and Brandic, I (2009). Cloud Computing and Emerging IT Platforms: Vision, Hype, and Reality for Delivering Computing as the 5th Utility. Future Generation Computer Systems, 25(6): 599-616.

[9] Khan, K.M. and Malluhi, Q. (2010). Establishing Trust in Cloud Computing, IT Professional, 12(5): 20 - 27.

[10] Sehgal, S. (2013) Road Towards Cloud Computing - What are the issues? - Part - I The Official blog of Simplilearn June 13, 2013 available at:// blog.simplilearn.com/it-service- management/roadtowards-cloud-computing-what- are-the-issues-part-i

[11] McKnight, D.H., Cummings, L. L. and Chervany, N. L. (1996). Trust Formation in New Organaizational Relationships. MIS Research Center, Carlson School of Management, University of Minnesota.

[12] Ba, S. and Paylou, P. A. (2002). Evidence of the Effect of Trust Building Technology in Electronic Markets: Price Premiums and Buyer Behaviour. MIS Quarterly, 26:243-268.

[13] Dasgupta, P. (2000) 'Trust as a Commodity', in Gambetta, D. (ed.) Trust: Making and Breaking Cooperative Relations, electronic edition, Department of Sociology, University of Oxford.

[14] Momani, M., Aboura, K., and Challa,S. (2007). RBATMWSN: Recursive Bayesian Approach to Trust Management in Wireless Sensor Networks, ISSNIP 2007 3rd International Conference on Intelligent Sensors, Sensor Networks and Information Processing Melbourne, Australia, pp. 347-352.

[15] Khan, K.M. and Malluhi, Q. (2010). Establishing Trust in Cloud Computing, IT Professional, 12(5): 20 - 27.

[16] Dingguo, Y., Nan, C. and Chengxiang, T. (2011). Research on Trust Cloud-Based Subjective Trust Management Model Under Open Network Environment. Information Technology Journal, 10: 759-768. 
[17] Silas, S., Rajsingh, E.B. and Ezra, K. (2012). Efficient Service Selection Middleware using ELECTRE Methodology for Cloud Environments. Information Technology Journal, 11: 868-875.

[18] Hada, P.S., Singh, R. and Meghwal, M.M. (2011). Security Agents: A Mobile Agent based Trust Model for Cloud Computing. International Journal of Computer Applications, 36(12): 12 - 15.

[19] Li, B., Cao, B., Wen, K. and Li, R.(2011). Trustworthy Assurance of Service Interoperation in Cloud Environment. International Journal of Automation and Computing, 8(3): $297-308$.

[20] Firdhous, M.,Ghazali, O. and Hassan, S. (2011). Trust Management in Cloud Computing: A Critical Review International Journal on Advances in ICT for Emerging Regions 201104 (02) : 24 - 36 critical review

[21] Sato, H., Kanai, A. and Tanimoto, Z. (2010). "A Cloud Trust Model in a Security Aware Cloud,"in 2010 10th IEEE/IPSJ International Symposium on Applications and the Internet (SAINT), Seoul, South Korea, pp. 121 - 124.

[22] Wang, T.F., Ye, B.S. Li, Y.W. and Yang, Y. (2010a). "Family Gene based Cloud Trust Model," in International Conference on Educational and Network Technology (ICENT), Qinhuangdao, China, pp. 540 - 544.

[23] Wang, T.F., Ye, B.S. Li, Y.W. and Zhu, L.S. (2010b). "Study on Enhancing Performance of Cloud Trust Model with Family Gene Technology," in $3^{\text {rd }}$ IEEE International Conference on Computer Science and Information Technology (ICCSIT), Chengdu, China, pp. 122 - 126.

[24] Manuel, P.D., Selve, T. and Abd-EI Barr, M.I. (2009). "Trust Management System for Grid and Cloud Resources," in 2009 First International Conference on Advanced Computing (ICAC 2009), December 13 - 15, 2009, Chennai, India, pp. 176 -181.

[25] Shen, Z., Yan, L.L.F. and Wu, X. (2010). "Cloud Computing System Based on Trusted Computing Platform," in 2010 International Conference on Intelligent Computation Technology and Automation (ICICTA), Changsha, China, pp. $942-945$.

[26] Shen, Z. and Tong, Q. (2010). "The Security of Cloud Computing System Enabled by Trusted Computing Technology," in the 2010 Proceedings of the 2nd International Conference on Signal Processing Systems (ICSPS), Dalian, China, pp. 11-15.

[27] Alhamad, M., Dillon, T. and Chang, E. (2010). 'SLA-based Trust Model for Cloud Computing,' in 13th International Conference on Network-Based Information Systems, Takayama, Japan.

[28] Li, X.Y., Zhou, L.T., Shi, Y. and Guo, Y. (2010). "A Trusted Computing Environment Model in Cloud Architecture", in 2010 Ninth International Conference on Machine Learning and Cybernetics (ICMLC), July 11 - 14, 2010, Qingdao, China, pp. 2843-2848.

[29] Fu, J., Wang, C., Yu, Z., Wang, J. and Sun, J.G. (2010). 'A Watermark-Aware Trusted Running Environment for Software Clouds,' in Fifth Annual ChinaGrid Conference (ChinaGrid), Guangzhou, China, pp. 144 - 151.

[30] Ranchal, R., Bhargava, B., Othmane, L.B., Lilien, L., Kim, A.,Kang, M. and Linderman, M.(2010). "Protection of Identity Information in Cloud Computing without Trusted Third Party," in 29th IEEE International Symposium on Reliable Distributed Systems, New Delhi, India, 2010, pp. 1060-9857.

[31] Takabi, H., Joshi, J.B.D. and Ahn, G.J. (2010). "SecureCloud: Towards a Comprehensive Security Framework for Cloud Computing Environments", in 34th Annual IEEE Computer Software and Applications Conference Workshops, Seoul, South Korea, pp. 393 - 398.

[32] Noor, T.H. and Sheng, Q.Z. (2011). Trust as a Service: A Framework for Trust Management in Cloud Environments School of Computer Science The University of Adelaide, Adelaide SA 5005, Australia
[33] Pawar,P.S., Rajarajan, M., Krishnan Nair, S. and Zisman, A.(2012). Trust Model for Optimized Cloud Services: In Dimitrakos et al. (Eds.): International Federation for Information Processing 2012, AICT 374, pp. $97-112$.

[34] Li, W., Ping,L., Qiu,Q. And Zhang, Q. (2012). Research on Trust Management Strategies in Cloud Computing Environment. Journal of Computational Information Systems, 8(4): 1757-1763

[35] Prajapati,S.K., Changder, S. and Sarkar, A.(2013). "Trust Management Model for Cloud Computing Environment", Proceedings of the International Conference on Computing, Communication and Advanced Network (ICCCAN 2013), March 15 - 17, India, pp. 1-5

[36] Wu, X., Zhang,R., Zeng, B. and Zhou, S. (2013). A trust evaluation model for cloud computing. International Conference on Information Technology and Quantitative Management (ITQM2013) Published by Elsevier B.V. Procedia Computer Science 17 ( 2013 ), pp. 1170 - 1177.

[37] Venkatesh, V. and Goyal, S. (2010). Expectation Disconfirmation and Technology Adoption: Polynomial Modeling and Response Surface Analysis1. MIS Quarterly 34(2): 281-303.

[38] Bhattacherjee, A., Perols, J. and Sanford, C. (2008). Information Technology Continuance: a theoretic extension and empirical test. Journal of Computer Information Systems, 49(1): 17-26.

[39] Bhattacherjee, A. and G. Premkumar (2004). Understanding changes in belief and attitude toward information technology usage: A theoretical model and longitudinal test. MIS Quarterly, 28(2): 229-254.

[40] Susarla, A., Barua, A. and Whinston, A. B. (2003). Understanding the Service Component of Application Service Provision: An Empirical Analysis of Satisfaction with ASP Services. MIS Quarterly, 27(1): 91123.

[41] Ekinci Y. and Sirakaya E. (2004). 'An Examination of the Antecedents and Consequences of Customer Satisfaction'. In: Crouch G.I., Perdue R.R., Timmermans H.J.P., and Uysal M. Consumer Psychology of Tourism,Hospitality and Leisure. Cambridge, MA: CABI Publishing, pp. 189-202.

[42] Churchill, G. A., and Surprenant, C. (1982). An investigation into the Determinants of Consumer Satisfaction. Journal of Marketing Research, 19: 491-504.

[43] Spreng, R. A., MacKenzie, S. B., and Olshavsky, R. W. (1996). A Reexamination of the Determinants of Consumer Satisfaction. Journal of Marketing, 60: 15-32.

[44] Oliver, R. L. (1980). A cognitive model of the antecedents and consequences of satisfaction decisions. Journal of Marketing Research, 17: 460-469.

[45] Erastus-Obilo, B. (2009). Reason Curve, Jury Competence, and the English Criminal Justice System: The Case for a 21 st Century Approach Universal-Publishers

[46] Pearl, J. (1988). Probabilistic reasoning in intelligent systems: networks of plausible inference, San Mateo, California, Morgan Kaufmann Publishers.

[47] Jensen, F.V. (1996). An Introduction to Bayesian Networks, Springer, New York.

[48] Wickremasinghe, B., Calheiros, R.N. and Buyya, R. (2010). CloudAnalyst: A CloudSim-based Visual Modeller for Analysing Cloud Computing Environments and Applications. Available at http://www.cloudbus.org/cloudsim/

[49] Moore, D., and McCabe, G. (2006). Introduction to the practice of statistics 4th ed.New York: Freeman.

[50] Jackson, S.L. (2008). Research Methods and Statistics: A Critical ThinkingApproach: A Critical Thinking Approach 3rd ed. WADSWORTH Cengage Learning Inc., USA. 